\title{
Evidence for the transfer of polychlorinated biphenyls, polychlorinated dibenzo- $p$-dioxins, and polychlorinated dibenzofurans from soil into biota
}

\author{
Xingru Zhao, Minghui Zheng *, Bing Zhang, Qinghua Zhang, Wenbin Liu \\ State Key Laboratory of Environmental Chemistry and Ecotoxicology, Research Center for Eco-Environmental Sciences, \\ Chinese Academy of Sciences, P.O. Box 2871, Beijing 100085, China
}

Received 13 September 2005; received in revised form 14 February 2006; accepted 16 February 2006

Available online 6 March 2006

\begin{abstract}
The concentrations of six indicator and co-planar polychlorinated biphenyls (PCBs), 17 polychlorinated dibenzo-p-dioxins, and polychlorinated dibenzofurans ( $\mathrm{PCDD} / \mathrm{Fs}$ ) were determined in soil and associated biota samples collected from a polluted and wasted farmland in southern China. The sum of six indicator PCBs (Nos 28, 52, 101, 138, 153 and 180) concentrations in biota samples were proportional to the total amount of PCBs that transferred from soil to the corresponding biota samples, and the sum six indicator PCB congeners in samples were about $20 \%$ of the total PCBs, respectively. The ratios of the sum six indicator PCBs and the total PCBs in samples collected in the same area were approximately equal. The sums of six indicator PCBs were proportional to the total PCBs that transferred from soil to plant, while the co-planar PCBs were not. Analysis of individual PCB and $\mathrm{PCDD} / \mathrm{F}$ congener signatures in soil revealed the original pollutant source after transportation and biodegradation for 14 years using principal component analysis (PCA). The pattern of PCBs in soils and plants could reflect the original pollution source after transportation and biodegradation for 14 years, while the pattern of PCBs in the terrestrial animals could not reflect the primary source. The consumption foods in this region such as foraging chicken eggs, foraging duck eggs, and loach (Misgurnus anguillicaudatus) were highly contaminated, the total toxicity equivalent (TEQ) was up to $784 \mathrm{pg}$ WHO-TEQ/g on basis lipid in foraging chicken eggs.
\end{abstract}

(C) 2006 Elsevier B.V. All rights reserved.

Keywords: PCBs; PCDD/Fs; Transfer; Biota; PCA

\section{Introduction}

Polychlorinated biphenyls (PCBs), polychlorinated dibenzo- $p$-dioxins, and polychlorinated dibenzofurans (PCDD/Fs) are ubiquitous environmental contaminants. $\mathrm{PCDD} / \mathrm{Fs}$ are formed or released unintentionally, and

\footnotetext{
* Corresponding author. Tel.: +86 106284 9172; fax: +86 106292 3563.

E-mail address: zhengmh@mail.rcees.ac.cn (M. Zheng).
}

there are still considerable uncertainties about their fluxes into the environment. On the other hand, PCBs are highly persistent molecules used as dielectric fluids, flame retardants, and industrial lubricant fluids. Because of their persistence and widespread distribution, the bioaccumulation of $\mathrm{PCBs}$ and $\mathrm{PCDD} / \mathrm{Fs}$ in aquatic ecosystems has been studied intensely for many years. However, there have been few studies of bioaccumulation in terrestrial ecosystems, especially in agricultural food chains. 
Soils are an important reservoir for persistent organic pollutants (POPs) (Harrad et al., 1994; Cousins and Jones, 1998), while plants lie in the first trophic level in the agricultural food chain, they play an important role in the global cycling and food chain transfer of PCBs and PCDD/Fs (McLachlan, 1996; Thomas et al., 1998). Some researchers have studied the pathway of background exposure to PCBs and PCDD/Fs in agricultural food chains, which was atmosphere-fodder-cattlecows' milk/beef (McLachlan, 1996; Theelen et al., 1993). However, there have been few studies on the transfer pathway of PCBs and PCDD/Fs from contaminated soil to biota (Chiou et al., 2001; McLachlan, 1996). It is well known that foods of agricultural origin, most especially animal fat, account for the majority of the human exposure to PCBs and PCDD/Fs (Theelen et al., 1993). Also some PCBs and PCDD/Fs contamination incidents have been reported in the agricultural food chain, such as the contamination of milk, butter and meat by the use of contaminated citrus pulp in feedstuffs (Malisch, 2000a), the Belgian dioxin episode in May 1999 in which the feed contained waste vegetable oil contaminated with residues of PCBs and PCDD/Fs (van Larebeke et al., 2001), and the 'natural' presence of PCDD/Fs in kaolinitic clays widely used as agent feed additives (Malisch, 2000b).

China produced PCBs from 1965 to 1974. The domestic products of technical PCBs were named $\mathrm{PCB}_{3}$ and $\mathrm{PCB}_{5}$, which compositions were almost similar to those of Arochlor 1242 and 1254, respectively (Jang et al., 1997). China's total production was $10,000 \mathrm{t}$ of which $9000 \mathrm{t}$ was $\mathrm{PCB}_{3}$ and $1000 \mathrm{t}$ was $\mathrm{PCB}_{5}$ (Qin et al., 2003). Most of $\mathrm{PCB}_{3}$ products have been used as dielectric fluids in electric capacitors, and most of $\mathrm{PCB}_{5}$ products as additives in paints (Jang et al., 1997). In 1989, illegal detaching of disused electric capacitors resulted in the PCBs pollution accident in southern China. Chu et al. (1999) and Bi et al. (2002) studied the PCB levels in paddy field near the pollution site in this region in 1993 and 1999.

One objective of this study was to obtain field data on levels of PCBs and PCDD/Fs in soil and biota samples in order to investigate the transfer of $\mathrm{PCBs}$ and $\mathrm{PCDD} / \mathrm{Fs}$ in a contaminated agricultural field. Other objectives were to explore whether the pattern of PCBs in soils can reflect the original pollution source after transportation and biodegradation for 14 years, and to determine whether the patterns of PCBs in some associated biota samples (e.g. soybean, earthworm, grass) were similar to those found in soil, using principal component analysis (PCA). The levels of individual PCB and PCDD/F congener were determined in soils and associated biota samples collected from the polluted soils using an isotope dilution high resolution gas chromatography and high resolution mass spectrometry (HRGC/HRMS) method, and the consumption food (i.e. foraging chicken eggs, foraging duck eggs, and fresh fish) collected from this region were also analyzed.

\section{Materials and methods}

\subsection{Sampling}

Samples were collected from polluted and wasted farmlands where electric capacitors were illegally dismantled in 1989.

In September 2003, the contaminated soil, and the biota samples associated with soil such as grass (Trigonotis Stev.), earthworms (L. terrestris), germinated soybeans scattering in the soil and the eggs of chicken foraged on the contaminated soil, were collected. The eggs of foraging duck were collected from the local farmers, and the loach (Misgurnus anguillicaudatus) samples were collected from a local river.

Soil sample was taken from the upper $5 \mathrm{~cm}$ soil layer and was a mixture of 8 subsamples collected in an area of $50 \mathrm{~m}^{2}$. Grass samples were obtained by cutting the whole grass after being rinsed in clean water on-site, and germinated soybean samples were rinsed in clean water and cut with scissors on-site. Four egg samples were collected and pooled in a clean jar. Forty earthworm samples were pooled from 8 subsamples, corresponding to the soil samples, rinsed in clean water and filleted onsite. Loach samples, 20 subsamples were pooled after being rinsed in clean water and filleted on-site. All samples were wrapped in aluminium foil twice and sealed in plastic bags to minimize the possibility of contamination. During the two-day sampling trip, the samples were stored in a cool box. Upon arrival in laboratory, the samples were immediately transferred to a freezer where they were stored until analysis. Samples were freeze-dried and then homogenized in an agate blender prior to analysis.

\subsection{Chemical analysis}

$\mathrm{PCBs}$ and $\mathrm{PCDD} / \mathrm{Fs}$ were analyzed following the method USEPA 1668A and USEPA 1613B modifications. Briefly, the samples were spiked with known amounts of a ${ }^{13} \mathrm{C}_{12}$-PCBs mixture (EPA 68A-LCS mixture, Wellington Laboratories) and a ${ }^{13} \mathrm{C}_{12}-\mathrm{PCDD} /$ Fs mixture (EPA 23ISS mixture, Wellington Laboratories), and mixed with anhydrous sodium sulfate, allowed the soil samples to equilibrate for 1 to $2 \mathrm{~h}$ and the biota 
samples to equilibrate for $18-24 \mathrm{~h}$. The soil samples were Soxhlet extracted with toluene for $24 \mathrm{~h}$, and the biota samples were Soxhlet extracted with $250 \mathrm{ml}$ methylene chloride:hexane 50:50 (v/v) for 18-24 h. The extracts of soybeans, eggs and loach samples were evaporated to $1 \mathrm{ml}$, and subsequently, a constant weight was obtained under a nitrogen stream, then the lipid contents were determined with gravimetric method. After the extracts were redissolved with hexane, the lipids were removed by anthropogenic isolation columns (described in 1668A method). Then, the extracts were purified with multi-layer silica gel columns. Afterwards, the extracts were fractionated by basic alumina columns. All of the fractions were concentrated for injection into HRGC/ HRMS. Identification and quantification of individual $\mathrm{PCB}$ and $\mathrm{PCDD} / \mathrm{F}$ congener were accomplished with a 6890 gas chromatograph (Agilent) coupled to an Autospec Ultima mass spectrometer (Waters, USA), at 10,000 resolving power (10\% valley definition). Chromatographic separation was achieved with a DB-5 ( $\mathrm{J}$ and W Scientific, CA, USA) fused-silica capillary column $(60 \mathrm{~m} \times 0.25 \mathrm{~mm} \times 0.25 \mu \mathrm{m})$.

Analytical quality control was applied to ensure the analysis of PCB and PCDD/Fs, such as a continuous monitoring of laboratory contamination based on the determination of a blank sample covering the whole analytical procedure, including extraction, cleanup and quantification. Recoveries of spiked soil with the calibration mixture were in the range of $60-95 \%$. CIL (Cambridge Isotope Laboratories) standard reference material (EDF - 2525 fish, EDF - 5183 soil ) was analyzed for selected PCB and PCDD/F congener, and reliable results were obtained by comparison of the data from our laboratory with those from material reference values.

\subsection{Principal component analysis}

The objective of PCA is to derive a few new components (principle components) as a linear combination of the original variables, which will provide a description of the data structure with a minimum loss of information. It has been applied successfully by some researchers to group the samples or to reveal the proximity between the sources of these compounds (Chu et al., 1999; Bi et al., 2002; Smith et al., 1990; Koesters and Hites, 1992).

PCA, based on the concentration of individual PCB and $\mathrm{PCDD} / \mathrm{F}$ congener, was used to extract principal components (PCs) that accounted for the major part of the data variation in PCB concentrations, and these PCs were related to the major PCB sources on the basis of both of these factor-loading values. The 6 indicator PCB and co-planar $\mathrm{PCB}$ congeners were treated as variables and the samples, and $\mathrm{PCB}_{3}$ and $\mathrm{PCB}_{5}$ were treated as cases. PCBs not detected (ND) were removed. The concentration data obtained for each congener in sample analysis was expressed as fractional parts of the total and normalized to sum equal to 100 . This normalization minimizes the influence of total concentration and permits a comparison of compositional similarities among samples. The eigenvectors were normal-varimax rotated to facilitate the interpretation of the results (Sakurai et al., 1998). Statistical analyses were carried out with SPSS 12.0 for Windows Release 12.0 (SPSS Inc.).

\section{Results and discussion}

\section{1. $P C B$ and $P C D D / F$ levels}

Levels of individual PCB congener, total PCBs and individual $\mathrm{PCDD} / \mathrm{F}$ congeners in soil and biota samples are shown in Table 1. The concentrations were reported on a lipid basis for loach and egg samples, and on dry weight for soil, earthworm, soybean and grass samples. The levels were found in the following order: Foraging chicken eggs (784 pg WHO-TEQ/g fat) $>$ earthworm (280 pg WHO-TEQ/g dw) > loach (190 pg WHO-TEQ/g fat) $>$ soil, grass (60 and $70 \mathrm{pg}$ WHO-TEQ/g dw) and foraging duck eggs ( $75 \mathrm{pg} \mathrm{WHO}-\mathrm{TEQ} / \mathrm{g}$ fat) $>$ the germinated soybeans scatting in the soil $(6.3 \mathrm{pg}$ WHOTEQ/g dw). All of the calculated TEQs were far higher than the limits proposed in the draft of the European Commission (EC) Regulation for food commercialization in the European countries (EC No.194/97): 5 pg WHO-TEQ/g fat for egg and 3 pg WHO-TEQ/g whole product for fish.

Schmid et al. (2002) reported PCDD/Fs levels in eggs of chicken that were feed with polluted kaolin in 1999 and found $21 \mathrm{pg}$ of I-TEQ/ g fat. van Larebeke et al. (2001) found that the levels of PCDD/Fs and PCB were 32 I-TEQ pg/g fat, and 393 WHO-TEQ ng/g fat in Belgian eggs from the incident of January-June 1999. In the present study, the $\mathrm{PCDD} / \mathrm{F}$ levels in foraging chicken eggs were higher than those found in eggs of chicken that were fed with polluted kaolin, but far lower than those found in the Belgian eggs from the incident of January-June 1999.

\subsection{PCA results and primary sources}

Using PCA, the loading plot (Figs. 1 and 3) and score plot (Figs. 2 and 4, PC1 vs PC2) were obtained, after normal-varimax rotation. For PCBs, Fig. 1 shows that $\mathrm{PC} 1$, which accounts for $46 \%$ of the variance of the 
Table 1

Concentrations of PCBs and PCDD/Fs in samples from the pollution region in China $(\mathrm{pg} / \mathrm{g})$

\begin{tabular}{|c|c|c|c|c|c|c|c|}
\hline & Soil (dry wt) & Earthworm (dry wt) & Grass (dry wt) & Bean (dry wt) & Chicken egg (fat) & Duck egg (fat) & Loach (fat) \\
\hline PCB77 & 25,194 & 61,278 & 24,012 & 2286 & 25,919 & 2510 & 32,165 \\
\hline PCB81 & 2357 & $<3$ & $<3$ & 350 & $<6$ & $<3$ & 4919 \\
\hline PCB 105 & 18,679 & 124,085 & 37,169 & 3009 & 301,899 & 5721 & 42,336 \\
\hline PCB118 & 31,375 & 238,503 & 65,659 & 5861 & 660,386 & 17,937 & 82,451 \\
\hline PCB114 & 673 & 11,197 & 3198 & 329 & 20,024 & 504 & 4631 \\
\hline PCB 126 & 487 & 2150 & 464 & 36 & 5949 & 600 & 503 \\
\hline PCB167 & 539 & 5511 & 1129 & 73 & 30,313 & 2622 & 1029 \\
\hline PCB 156 & 943 & 12,358 & 2939 & 197 & 84,632 & 6129 & 2769 \\
\hline PCB 157 & 252 & 2692 & 786 & 52 & 20266 & 684 & 738 \\
\hline PCB169 & $<1$ & $<2.5$ & 11 & 0.84 & 223 & 38 & 12 \\
\hline PCB189 & 114 & 562 & 109 & 6.2 & 4541 & 793 & 87 \\
\hline Total co-planar PCBs & 130,057 & 458,336 & 135,476 & 12,200 & $1,154,152$ & 37,538 & 171,640 \\
\hline PCB28 & 101,487 & 540,921 & 306,251 & 41,127 & 646,802 & 44,425 & 578,598 \\
\hline PCB52 & 34,880 & 291,448 & 131,875 & 26,596 & 64,645 & 44,595 & 344,354 \\
\hline PCB101 & 17,238 & 209,857 & 93,121 & 8359 & 62,948 & 8200 & 150,516 \\
\hline PCB138 & 10,317 & 224,167 & 42,325 & 2747 & 584,372 & 92,369 & 38,650 \\
\hline PCB153 & 8820 & 149,200 & 37,984 & 2954 & 637,661 & 117,963 & 41,556 \\
\hline PCB 180 & 1914 & 24,781 & 4681 & 323 & 103,280 & 56,955 & 4549 \\
\hline Total indicator PCBs & 174,656 & $1,440,374$ & 616,237 & 82,106 & $2,099,708$ & 364,507 & $1,158,223$ \\
\hline Total PCBs & 739,386 & $58,902,752$ & $2,799,929$ & 426,165 & $9,373,673$ & $1,658,528$ & $5,951,276$ \\
\hline WHO-TEQ PCBs & 57 & 271 & 63 & 5 & 759 & 67 & 71 \\
\hline $2,3,7,8,-\mathrm{TCDF}$ & 3.8 & 18 & 10 & 0.44 & 115 & 15 & 140 \\
\hline $1,2,3,7,8,-\mathrm{PeCDF}$ & 2.9 & 17 & 7.7 & 0.23 & 117 & 12 & 60 \\
\hline $1,2,3,6,7,8-\mathrm{HxCDF}$ & 1.9 & 13 & 4.9 & 0.17 & $<3$ & 4 & 19 \\
\hline $1,2,3,4,6,7,8-\mathrm{HpCDF}$ & 4.6 & 53 & 12 & 0.60 & 42 & 3.8 & 11 \\
\hline $\mathrm{OCDF}$ & 0.87 & 14 & 2.3 & 0.29 & 7 & $<3$ & 1.74 \\
\hline Total TCDF & 59 & 173 & 154 & 4.7 & 133 & 83 & 304 \\
\hline Total PeCDF & 36 & 141 & 94 & 3.1 & 217 & 56 & 248 \\
\hline Total HxCDF & 23 & 93 & 60 & 2.4 & 141 & 25 & 81 \\
\hline Total HpCDF & 6 & 63 & 16 & 0.72 & 64 & 212 & 16 \\
\hline $2,3,7,8-\mathrm{TCDD}$ & 0.84 & 1.2 & 2.2 & 0.33 & 4.9 & 1.8 & 39 \\
\hline $1,2,3,7,8-\mathrm{PeCDD}$ & 0.91 & 3.6 & 2.4 & 0.82 & $<0.5$ & 3.2 & 58 \\
\hline $1,2,3,6,7,8-\mathrm{HxCDD}$ & 0.72 & 4.1 & 1.9 & 0 & 17 & 2.6 & 25 \\
\hline $1,2,3,4,6,7,8-\mathrm{HpCDD}$ & 1.8 & 14 & 4.7 & 0.76 & 17 & 2.2 & 10 \\
\hline OCDD & 7.60 & 91 & 20 & 7.9 & 28 & 17 & 60 \\
\hline Total TCDD & 59 & 81 & 155 & 3.8 & 7.1 & 5.5 & 39 \\
\hline Total PeCDD & 60 & 114 & 157 & 3.6 & $<0.5$ & 6.7 & 62 \\
\hline Total HxCDD & 22 & 71 & 59 & 1.7 & 24 & 8.2 & 85 \\
\hline Total HpCDD & 4.2 & 29 & 11 & 1.2 & 19 & 7.1 & 60 \\
\hline WHO-TEQ PCDD/Fs & 2.6 & 9.8 & 6.8 & 1.2 & 25 & 7.8 & 119 \\
\hline Total WHO-TEQ & 60 & 280 & 70 & 6.3 & 784 & 75 & 190 \\
\hline Total PCDD/Fs & 277.67 & 870 & 728.3 & 29 & 640.1 & 420.5 & 956.74 \\
\hline $\mathrm{PCBs} / \mathrm{PCDD} / \mathrm{Fs}$ & 2663 & 67,704 & 3844 & 14,695 & 14,644 & 3944 & 6220 \\
\hline TEQ $_{\mathrm{PCB}} /$ total TEQ & 0.93 & 0.97 & 0.90 & 0.79 & 0.97 & 0.90 & 0.37 \\
\hline
\end{tabular}

dataset, is positively determined by the co-planar PCBs $189,169,167,126,156$, as well as the indicator PCBs 138, 153 and 180. PC2 accounts for $20 \%$ of the total variance and is characterized by the co-planar PCBs 118,105 and 114, as well as the indicator PCBs 101 . The different correlation degrees of PCB congeners are manifest. The score plots obtained from the first two principal components were shown in Fig. 2. It shows that the soil, earthworm, soybean, grass samples form one group with $\mathrm{PCB}_{3}$, the eggs of foraging chicken and foraging duck form the other group. The similarity among soil, plant, earthworm and $\mathrm{PCB}_{3}$ isomeric patterns suggested that the original source of the PCBs was $\mathrm{PCB}_{3}$ used as dielectric fluids of electric capacitors. The eggs of foraging chicken and foraging duck didn't form the same group with $\mathrm{PCB}_{3}$, it may be related with the routes of the different bioaccumulation and the metabolism of chicken and duck.

For PCDD/Fs, the loading plot (Fig. 3) shows that $\mathrm{PC} 1$ accounts for $36 \%$ of the variance and is 


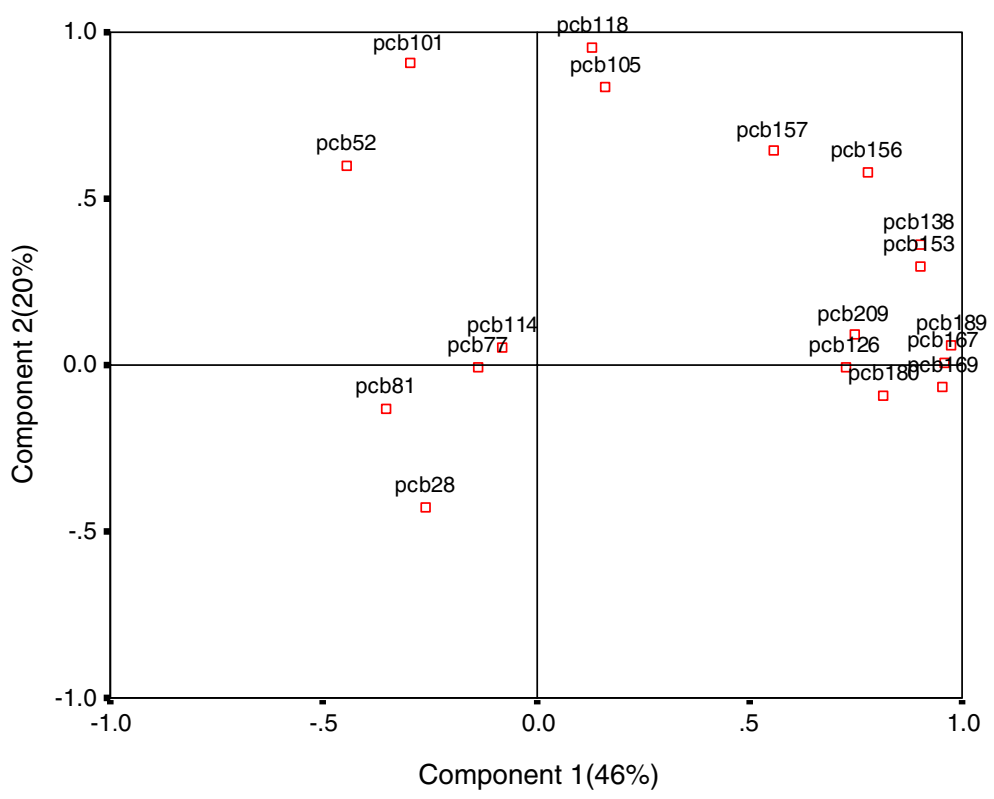

Fig. 1. Two-dimensional principal component loading plot obtained from the normalized PCBs data correlation matrix of samples from the pollution area.

characterized by $2,3,7,8-\mathrm{TCDD}, 1,2,3,7,8-\mathrm{PeCDD}$, and $1,2,3,6,7,8-\mathrm{HxCDD}$. PC2 accounts for $24 \%$ of the total variance and is characterized by $1,2,3,4,6,7,8-\mathrm{HpCDD}$, and 1,2,3,4,6,7,8-HpCDF. In score plot (Fig. 4), the soil, earthworm, soybean, and vegetable form one group with $\mathrm{PCB}_{3}$. The similarity among soil, plant, earthworm and $\mathrm{PCB}_{3}$ isomeric patterns suggested that the primary source of the PCDD/Fs was the impurity contained in the technical PCB mixtures. The eggs of foraging chicken are characterized by $1,2,3,4,6,7,8-\mathrm{HpCDD}$, $1,2,3,4,6,7,8$-HpCDF and loach samples are characterized by 2,3,7,8-TCDD, 1,2,3,7,8-PeCDD, and $1,2,3,6,7,8-\mathrm{HxCDD}$. The congener patterns of the eggs of foraging chicken and foraging duck, and loach are

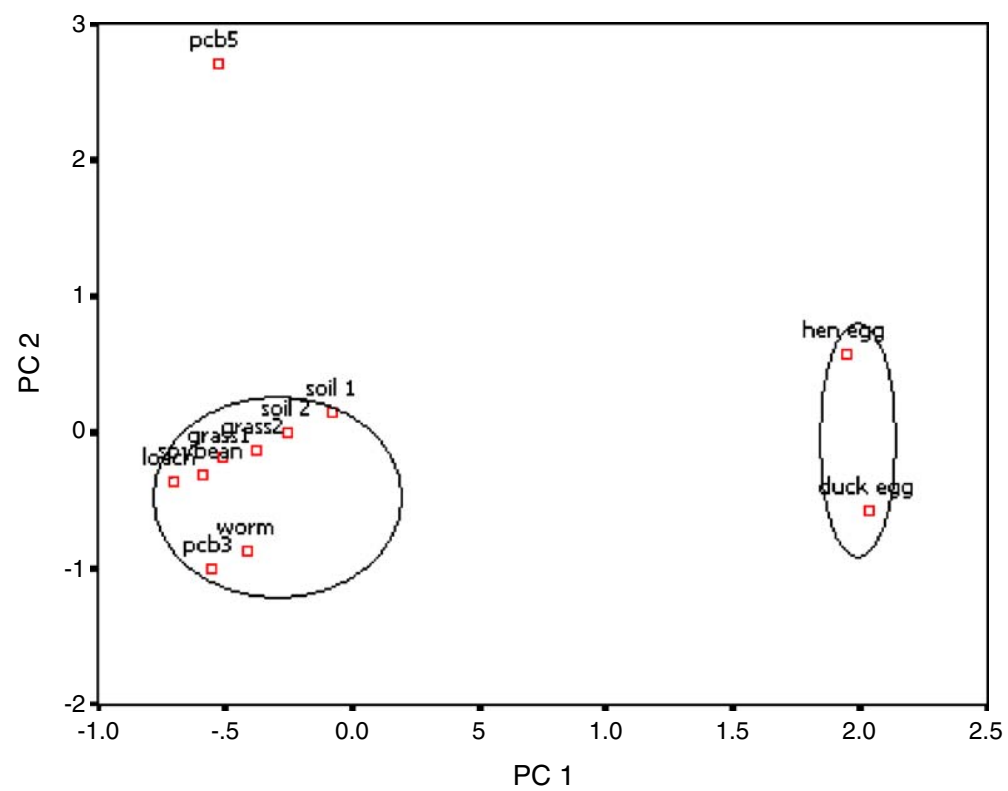

Fig. 2. Two-dimensional principal component score plot obtained from the normalized PCBs data correlation matrix samples from the pollution area. 


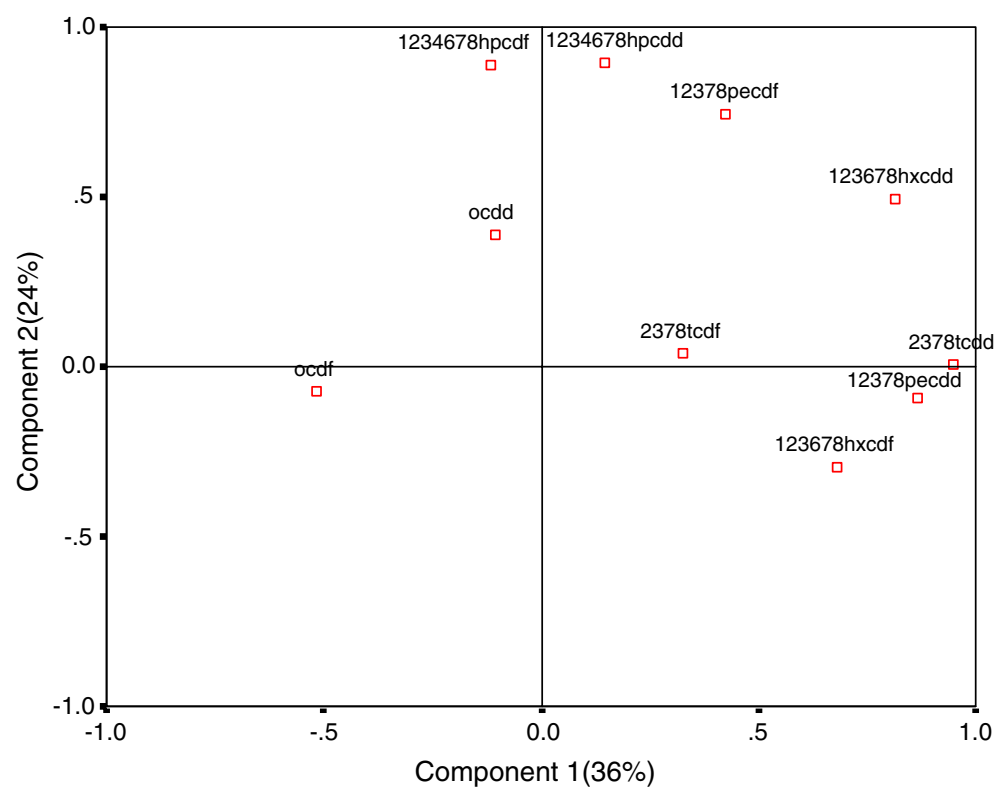

Fig. 3. Two-dimensional principal component loading plot obtained from the normalized PCDD/Fs data correlation matrix of samples from the pollution area.

different from $\mathrm{PCB}_{3}$, and it was probably related with the routes of the different bioaccumulation and the metabolism of chicken and duck, or there were some other contamination sources.

In the Belgian PCB and PCDD/F Crisis (van Larebeke et al., 2001), Schmid et al. (2002) confirmed the contamination source was transformer oil by the following reasons: $\mathrm{PCDD} / \mathrm{F}$ measurements showed a clear predominance of PCDF over PCDD congeners, a ratio of PCDD/Fs and PCBs was approximately $1: 50,000$ in eggs, and a PCB fingerprint resembled that of an Arochlor mixture (50:50 mixture of Arochlors 1254 and

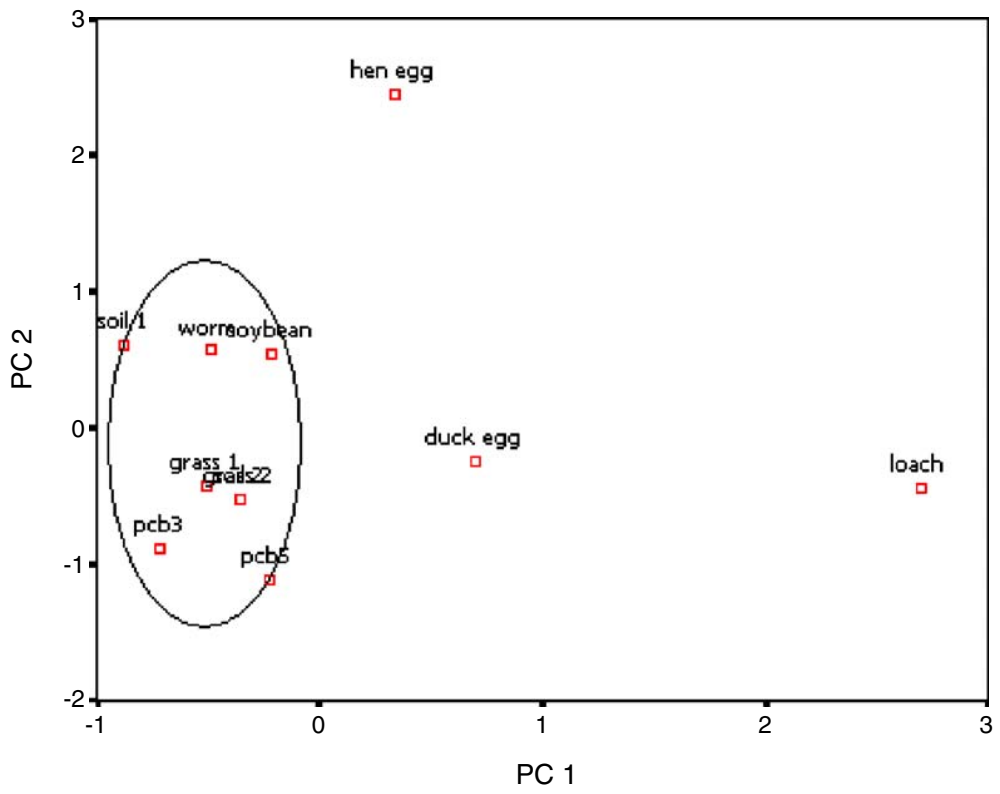

Fig. 4. Two-dimensional principal component score plot obtained from the normalized PCDD/Fs data correlation matrix of samples from the pollution area. 
1260), in particular, the PCBs contributed significantly greater to toxic equivalents (TEQ) than PCDD/Fs. In this study, owing to the transport and biodegradation of PCBs and PCDD/Fs for 14 years, the ratios of PCBs and $\mathrm{PCDD} / \mathrm{Fs}$ were different from those in $\mathrm{PCB}_{3}(160,000)$ and $\mathrm{PCB}_{5}(130,000)$ (Li and Jiang, 1995), but the PCBs in the analyzed samples contributed significantly greater to toxic equivalents (TEQ) than PCDD/Fs except for loach samples. According to the results of PCA and the ratios of $\mathrm{PCBs}$ and $\mathrm{PCDD} / \mathrm{Fs}$, the $\mathrm{PCBs}$ and $\mathrm{PCDD} / \mathrm{Fs}$ primary source in the analyzed sample was $\mathrm{PCB}_{3}$ except for the loach sample.

\subsection{Soil and plants}

The total PCB concentrations were $739 \mu \mathrm{g} / \mathrm{kg}$ dry weight in soil, $2800 \mu \mathrm{g} / \mathrm{kg}$ dry weight in grass and $426 \mu \mathrm{g} / \mathrm{kg}$ dry weight in soybeans, respectively. The sums of six indicator PCB congeners were proportional to the total amount of $\mathrm{PCBs}$ that transferred from soil to plants, but the co-planar PCB congeners were not the case. The ratios of the sums of six indicator PCBs and the total PCBs in samples collected in this area were approximately equal, it was about $20 \%$.

The phenomenon found in this study may be explained by previous studies. Soils play an important role in the global fate (Harrad et al., 1994; Wild and Jones, 1995), and vegetation plays an important role in the global cycling and food chain transfer of POPs (Chiou et al., 2001). Plants/crops also could accumulate organic chemicals from contaminated soils through the plant water, lipid and soil interstitial water (Chiou et al., 2001). It has been widely reported that hydrophobic compounds were not subject to significant translocation in plants (McLachlan, 1996; Harner et al., 1995). Welsch-Pausch et al. (1995) reported that PCB and similar compounds reached grass and other vegetation principally via atmospheric deposition. Thomas et al. (1998) also demonstrated that the vegetation approached equilibrium with the air rather rapidly.

The physical-chemical properties of the compound were of importance in the exchange processes. Volatilization of organic compounds from the soil was controlled by the compound vapor pressure and water solubility. The steric factors of the compounds could also be of importance for volatilization (Thomas et al., 1998). McLachlan et al. (1996) demonstrated that some di-ortho PCB congeners (i.e. PCBs 28, 52, 101, 104, 153, 138, $180,194)$ fugacity in the atmosphere and the contaminated soil was close equilibrium in the same season. The lower chlorinated PCBs in the leaves were in a nearequilibrium state with the atmosphere. In this study, the six indicator PCB congeners were of di-ortho PCB, so the results suggested that the pathway of transfer of some di-ortho PCB congeners from contaminated soil to leafy vegetables might be soil-air-leafy vegetables, and the di-ortho PCB congeners might be dominated in the transfer of PCBs in environmental compartments.

With respect to the primary source identified, the pattern of PCBs and PCDD/Fs in soils and plants could reflect the original pollution source using PCA, after the soil had been contaminated for 14 years. It may be because that PCBs taken up by vegetation might enter the soil when plant material fell into the ground and decayed (McLachlan and Horstmann, 1998). The higher chlorinated PCBs congeners tended to be absorbed in particles and to settle near source by dry or wet deposition. Bobovnikova et al. (2000) also observed that the PCBs profiles were similar to the pattern of Arochlor 1242 in the leafy vegetable and the corresponding soil from the vicinity of a capacitor plant, after the plant had stopped using Arochlor 1242 for 10 years. The results of PCA also showed that soil samples were characterized by higher chlorinated PCBs, and plant samples were characterized by lower chlorinated PCBs. Chu et al. (1999) and Bi et al. (2002) also reported that PCBs 28 and 52 decreased, while PCBs 153 and 138 increased from 1993 to 1997 in background paddy soil.

\subsection{Eggs and loaches}

The total WHO-TEQ (TEQ $\left.{ }_{\mathrm{PCDD} / \mathrm{F}}+\mathrm{TEQ}_{\mathrm{PCB}}\right)$ was up to $784 \mathrm{pg} / \mathrm{g}$ on fat basis in forging chicken eggs, and the contribution of co-planar PCBs to the total TEQ was $97 \%$. Similar contribution was observed in forging duck eggs. But in loach sample, the main contribution to the total TEQ was $63 \%$ from PCDD/Fs. All the total TEQ values were far above the limits proposed in the draft of the EC Regulation (EC No.194/97). The terrestrial animal fat accounted for the majority of the human exposure to PCBs and PCDD/Fs (Theelen et al., 1993). So if the residents dieted mainly on these foods, the highly contaminated consumption possibly posed a risk to the local residents. Some studies showed that PCDD/Fs in foraging chicken and cows were related to local soil contamination (Chang et al., 1989; Stephens et al., 1995; Schuler et al., 1997). The pathways of the soil related exposure of chicken were: ingestion of soil, ingestion of organisms (such as annelids etc.), inhalation of dust, and skin contact. Schuler et al. (1997) also studied the transfer of PCDD/Fs from soil into eggs of foraging chicken, the increased level of PCDD/Fs was attributed to the level of PCDD/Fs in corresponding soil, compared to eggs of hens kept without soil contact. 
The PCA results indicated that the individual PCB and $\mathrm{PCDD} / \mathrm{F}$ congener signatures in these samples were not similar to the soil and plant samples with the exception of the individual PCB congener signatures in loach sample. This difference may be related to the routes of the different bioaccumulation and the metabolism of chicken, duck and loach. So the patterns of PCBs and PCDD/Fs congeners in eggs and loach could not reflect the primary pollution source.

Similar to the results obtained from soil and plants, the ratios of the sum six indicator PCBs and the total PCBs in these organisms were close equal (20\%). It was observed in this study that the ratios of the sum six indicator PCBs congeners and the total PCBs were nearly constant in environmental compartments contacting directly with air in the same season. It might be due to the fugacity of moderately hydrophobic and moderately volatile persistent chemicals such as the lower chlorinated biphenyls (McLachlan, 1996) and some di-ortho PCBs congeners remain relatively constant throughout the agricultural food chain, from air to animal food products, however further study needs to do.

\subsection{Earthworms}

In the present study, it was observed that the earthworm had high bioaccumulation. The total PCB level and WHO-TEQ were up to $59 \mu \mathrm{g} / \mathrm{g}$ and $280 \mathrm{pg} / \mathrm{g}$ based on dry weight, and the total PCB level in its surrounding soil was only $740 \mathrm{ng} / \mathrm{g}$ based on dry weight. The PCA result indicated that the $\mathrm{PCB}$ and $\mathrm{PCDD} / \mathrm{F}$ patterns in earthworm were similar to those in its surrounding soil and $\mathrm{PCB}_{3}$. Similar result was also obtained by Singer et al. (2001); they reported that the patterns of PCBs in earthworm were similar to those in its surrounding soil. About the transport of the six indicator PCBs congeners from soil to earthworm, the ratio $(2.4 \%)$ of the sum six indicator PCBs and the total PCBs was different from those in other samples, the reason was unclear, may be it grows in subsurface soil, could not contact and approach equilibrium with the air. However, it needs further study to evidence the nature.

\section{Conclusion}

The abundance field data on PCB and PCDD/F levels in soil and biota samples from the contamination spot provided useful information about the transfer of PCBs and $\mathrm{PCDD} / \mathrm{Fs}$ in a contamination agricultural ecosystem. The pattern of PCBs in soils and plants could reflect the original pollution source after transportation and biodegradation for 14 years, but the pattern of PCBs in the terrestrial animals could not reflect the primary source. In this study, we also observed some interesting findings such as: the ratios of the sum six indicator PCBs and the total PCBs in samples collected in the same area were approximately equal. The sums of six indicator PCBs were proportional to the total PCBs that transferred from soil to plant, while the co-planar PCBs were not.

\section{Acknowledgements}

This study is supported by National 973 Project (2003CB415006) and the National Natural Science foundation of China (40332023).

\section{References}

Bi X, Chu S, Meng Q, Xu X. Movement and retention of polychlorinated biphenyls in a paddy field of Wen Tai area in China. Agric Ecosyst Environ 2002;89:241-52.

Bobovnikova TsI, Alekseeva LB, Dibtseva AV, Chernik GV, Orlinsky DB, Priputina IV, et al. The influence of a capacitor plant in Serpukhov on vegetable contamination by polychlorinated biphenyls. Sci Total Environ 2000;246:51-6.

Chang RR, Hayward D, Goldman L, Harnly M, Flattery J, Stephens RD. Foraging farm animals as biomonitors for dioxin contamination. Chemosphere 1989;19:481-6.

Chiou CT, Sheng G, Manes MA. Partition-limited model for the plant uptake of organic contaminants from soil and water. Environ Sci Technol 2001;35:1437-44.

Chu S, Cai M, Xu X. Soil-plant transfer of polychlorinated biphenyls in paddy fields. Sci Total Environ 1999;234:119-26.

Cousins IT, Jones KC. Air-soil exchange of semivolatile organic compounds (SOCs) in the UK. Environ Pollut 1998;102 (1):105-18.

EC No. 194/97. Setting maximum levels for certain contaminants in foodstuffs, amending commission regulation EC No. 194/97 of 31 January 1977; DG ENTR/E/1GS D (99); Brussels, Belgium, January 2000.

Harner T, Mackay D, Jones KC. Model of the long-term exchange of PCBs between soil and the atmosphere in the southern UK. Environ Sci Technol 1995;29:1200-9.

Harrad SJ, Sewart AP, Alcock R, Boumphrey R, Burnett V, DuarteDavidson R, et al. Polychlorinated biphenyls (PCBs) in the British environment: sinks sources and temporal trends. Environ Pollut 1994;85:131-46.

Jang K, Li L, Chen Y, Jin J. Determination of PCDD/Fs and co-planar PCBs in Chinese commercial PCBs and emission from a testing incinerator. Chemosphere 1997;34:941-50.

Koesters CJ, Hites RA. Wet and dry deposition of chlorinated dioxins and furans. Environ Sci Technol 1992;26:1375-82.

Li LJ, Jiang K. Determination of toxic equivalents of PCDD/Fs in two Chinese commercial PCBs by ${ }^{13} \mathrm{C}$ isotope dilution method. Acta Sci Circumstantiae (Chinese) 1995;15:433-9.

Malisch R. Increase of PCDD/F-contamination of milk, butter and meat samples by use of contamination citrus pulp. Chemosphere 2000a;40:1041-53.

Malisch R. PCDD/F in kaolinitic clays and its relevance for feeding stuff, food and cosmetics. Organohalog Compd 2000b;47:326-8. 
McLachlan MS. Bioaccumulation of hydrophobic chemicals in agricultural food chains. Environ Sci Technol 1996;30:252-9.

McLachlan MS, Horstmann M. Forest as filters of airborne organic pollutants: a model. Environ Sci Technol 1998;32:413-20.

Qin ZF, Zhou JM, Chu SG, Xu XB. Effects of Chinese domestic polychlorinated biphenyls (PCBs) on gonadal differentiation in Xenopus laevvis. Environ Health Perspect 2003;111:553-6.

Sakurai T, Suzuki N, Masunaga S, Nakanishi J. Origin attribution of polychlorinated dibenzo- $p$-dioxins and dibenzofurans in sediment and soil from a Japanese freshwater lake area through congenerspecific data analysis. Chemosphere 1998;37:2211-24.

Schmid P, Guier E, Degen S, Zennegg M, Kuchen A, Wüthrich C. Levels of polychlorinated dibenzo- $p$-dioxins and dibenzofurans in food of animal origin. The Swiss dioxin monitoring program. J Agric Food Chem 2002;50:7482-7.

Schuler F, Schmid P, Schlatter Ch. The transfer of polychlorinated dibenzo- $p$-dioxins and dibenzofurans from soil into eggs of foraging chicken. Chemosphere 1997;34:711-8.

Singer AC, Jury W, Luepromchai E, Yahng C-S, Crowely DE. Contribution of earthworms to PCB bioremediation. Soil Biol Biochem 2001;33:765-76.

Smith RM, O'Keefe PW, Aldous KM, Valente H, Connor SP, Donnelly RJ. Chlorinated dibenzofurans and dioxins in atmospheric samples from cities in New York. Environ Sci Technol 1990;24:1502-6.
Stephens RD, Petreas MX, Hayward DG. Biotransfer and bioaccumulation of dioxins and furans from soil: chickens as a model for forging animals. Sci Total Environ 1995;175:253-73.

Theelen RMC, Liem AKD, Slob W, van Wijnen JH. Intake of 2,3,7,8 chlorine substituted dioxins, furans, and planar PCBs from food in the Netherlands: median and distribution. Chemosphere 1993;27:1625-35.

Thomas GO, Sweetman AJ, Ockenden WA, Mackay D, Jones KC. Air-pasture transfer of PCBs. Environ Sci Technol 1998;32: 936-42.

van Larebeke N, Hens L, Schepens P, Covaci A, Baeyens J, Everaert $\mathrm{K}$, et al. The Belgian PCB and dioxin incident of January-June 1999: exposure data and potential impact on health. Environ Health Perspect 2001;109:1-21.

Welsch-Pausch K, McLachlan MS, Umlauf G. Determination of the principal pathways of polychlorinated dibenzo- $p$-dioxins and dibenzofurans to Lolium multiflorum(welsh ray grass). Environ Sci Technol 1995:1090-8.

Wild SR, Jones KC. Polynuclear aromatic hydrocarbons in the United Kingdom environment: a preliminary source inventory and budget. Environ Pollut 1995;88:91-108. 